

Revista Científica General José María Córdova

ISSN 1900-6586 (impreso), 2500-7645 (en línea)

Volumen 16, Número 22, abril-junio 2018, pp. 133-161

http://dx.doi.org/10.21830/19006586.325

Citación: Franco Ruiz, R. (2018, abril-junio). Pensamiento contable latinoamericano: entre colonialismo intelectual y ciencia propia. Rev. Cient. Gen. José María Córdova, 16 (22), 133-161.

DOI: http://dx.doi.org/10.21830/19006586.325

\title{
Pensamiento contable latinoamericano: entre colonialismo intelectual y ciencia propia
}

Sección: Historia

Artículo de investigación científica y tecnológica

Rafael Franco Ruiz
Universidad Libre, Bogota, Colombia

Latin American accounting thought: intellectual colonialism and own science

Pensamento contábil latino-americano: colonialismo intelectual e ciência propia

Pensée comptable latino-américaine: colonialisme intellectuel et science propre

Recibido: 12 de junio de 2016 • Aceptado: 14 de marzo de 2018

* https://orcid.org/0000-0002-9532-8927 - Contacto: rafael.francor@unilibrebog.edu.co 
Resumen. Se aborda una genealogía crítica del pensamiento contable latinoamericano, integrando teorías y aplicaciones que determinan la contabilidad como un saber social, desde la dinámica de dos tendencias rivales, una derivada de esfuerzos autóctonos y otra orientada a la transculturación que busca sustituirla por una sumatoria de modelos especializados que regulan prácticas de información financiera para satisfacer intereses hegemónicos. Se discute que el objeto de estudio de la contabilidad como ciencia social es el complejo sistémico de naturaleza, cultura, población y economía en sus relaciones con transacciones sociales. Se concluye que para superar el actual reduccionismo financiero se precisa solucionar las anomalías tradicionales inherentes al patrimonio-propiedad, para avanzar hacia una medición de eficacia social, mediante la formación de escuelas de pensamiento contable autóctonas que rompan el circulo vicioso de las colonizaciones continuadas, buscando la interacción instrumental de variables tales como clasificación, medición, valoración, representación, interpretación, control y evaluación de hechos sociales.

Palabras clave: contabilidad crítica; contabilidad integral; hermenéutica contable; neo-patrimonialismo; pensamiento contable latinoamericano.

Abstract. A critical genealogy of Latin American accounting thought has been addressed, integrating theories and applications that define accounting as social knowledge. It takes into account the dynamics of two opposing tendencies, one of these derived from indigenous efforts and the other one involved towards transculturation which purports to replace it by a buildup of specialized models regulating financial information practices, for them to satisfy hegemonic interests. It is argued that the object of study of accounting as a social science is the systemic complexity of nature, culture, population, and economy in its relations with social transactions. It is concluded that to overcome the current financial reductionism; it is necessary to elucidate the traditional anomalies concerning patrimony-property. To advance towards measuring the social effectiveness, through the formation of autochthonous schools of accounting thought that break the vicious circle of the continued colonization, looking for the instrumental interaction of variables such as classification, measurement, assessment, representation, interpretation, control, and evaluation of social facts.

Keywords: accounting hermeneutics; comprehensive accounting; critical accounting; Latin American accounting thought; neo-patrimonialism.

Resumo. Aborda-se uma genealogia do pensamento contábil latino-americano, integrando teorias e aplicaçôes que determinam a contabilidade como um saber social, tomando em plena consideraçáo a dinâmica de duas tendências rivais, uma delas derivada de alguns esforços nativos e dirigida à transculturalizaçáo que busca a substituiçáo por uma somatória de modelos de especialidades que regulam a prática de informaçáo financeira para satisfazer interesses hegemônicos. É discutido que o objeto de estudo da contabilidade como ciência social é o sistema complexo de natureza, cultura, população e economia, além de relaçôes com transaçōes sociais. Se conclui que para superar o reducionismo real financeiro é precisa solucionar as anomalias tradicionais do patrimônio-propriedade para avançar no sentido de uma consolidaçáo da eficácia social, mediante a formaçáo de escolas de pensamento contábil genuínas que rompam o círculo vicioso das colonizaçóes continuadas, buscando o a interação instrumental de variáveis como: classificação, medição, valoração, representação, interpretação, controle e avaliação de social fatos.

Palavras-chave: contabilidade crítica, contabilidade integral; hermenêutica contábil; neopatrimonialismo; pensamento contábil latino americano.

Résumé. Une généalogie critique de la pensée comptable latino-américaine est abordée, en intégrant des théories et des applications qui déterminent la comptabilité comme une connaissance sociale, tenant pleinement compte de la dynamique de deux tendances rivales, l'une d'elles dérivée de quelques efforts autochtones et l'autre orientés vers une transculturation qui a pour but la remplacer, par voie de sommation de modèles spécialisés qui réglementent des pratiques d'information financière pour satisfaire des intérêts hégémoniques. On examine que l'objet d'étude de la comptabilité en tant que science sociale est le complexe systémique de nature, culture, population et économie dans ses liens avec des transactions sociales. Il est conclu que pour surmonter le réductionnisme financier actuel, il est nécessaire de résoudre les anomalies traditionnelles inhérentes au patrimoine-propriété, pour avancer vers une mesure de l'efficacité sociale, grâce à la formation des écoles de pensé comptable autochtone qui rompent le cercle vicieux des colonisations continues, à la recherche de l'interaction instrumentale de variables telles que classification, mesure, évaluation, représentation, interprétation, contrôle et évaluation des faits sociaux.

Mots-clés : comptabilité critique ; comptabilité globale ; herméneutique comptable ; néo-patrimonialisme ; pensée comptable latino-américaine. 


\section{Introducción}

Se debe avanzar en el objetivo de señalar nuevos escenarios para los desarrollos teóricos de la contabilidad, a partir del reconocimiento de la producción en América Latina que señalen caminos identitarios del conocimiento contable, alternativos al saber oficial derivado de procesos de colonización conceptual e instrumental.

Este es un trabajo de revisión, un desarrollo crítico de la teoría y técnica contable, constituyendo la hermenéutica el fundamento central del método de investigación, iluminando un camino de interpretaciones y comprensiones, identificador de anomalías en la evolución histórica del pensamiento contable, las cuales se constituyen en el objeto de la construcción de soluciones mediante la identificación y desarrollo del pensamiento contable de América Latina.

En el proceso crítico se estudiaron las carencias históricas de la contabilidad, constituidas por la confusión entre conocimiento y regulación (Franco, 2011, pp. 51-60), su consideración como frutos secuenciales de colonizaciones contables, las anomalías surgidas de la fragmentación cognitiva contable (Franco, 1998, p. 243), así como sus dimensiones, intencionalidades, prácticas, intereses y valores.

El proceso contable conduce a una redefinición de la contabilidad, la caracterización de su naturaleza social que tiene por objeto la construcción de representaciones sociales (Franco, 1998, pp. 231-247), señalando el fin de una etapa de segmentación por la identificación de teorías integradoras como las formuladas alrededor del neo-patrimonialismo (Lopes de Sa, 1992) las bases de una teoría general de la contabilidad (Garcia Casella, 2001) o las perspectivas contamétricas (Franco, 1998) contra las visiones parciales que a partir de la división funcional del trabajo, con base en el principio de especialización, postulada por la administración científica, establecieron la existencia de diversas contabilidades con sus propios marcos conceptuales y procedimientos técnicos; la nueva concepción permite consolidar las condiciones para el desarrollo de la contabilidad como ciencia social. Es importante aclarar que desde la corriente crítico-interpretativa de la contabilidad, se ha insistido en reconocer la naturaleza social de la contabilidad (Hopwood, 2000), pero no se han aportado desarrollos, dado que no existe una producción teórica ni tecnológica, pues su acción se ha concentrado en las acciones de interpretación y crítica (Franco, 2013).

Las reformulaciones teóricas se constituyen en marco conceptual de una teoría contable alternativa centrada en la sociedad y no en las finanzas, posibilitando que a partir de una información objetiva, se desarrollen procesos de valoración y representación subjetivo-objetivos que consulten la dimensión temporal, los intereses y valores de los grupos de interés y fundamenten sus evaluaciones desde sus propias perspectivas, eliminando sesgos hacia determinado grupo como ha ocurrido en la contabilidad financiera. Algunos autores han abordado temáticas enunciadas como sociales, pero resulta importante afirmar que solo lo han hecho desde la perspectiva de la economía (García, 2002) y desde 
el derecho (Mattesich, 2002) si se considera que la relación de agencia determina que la contabilidad describe las relaciones principal-agente.

Se abre un escenario extenso para la investigación contable en que no es posible avanzar con diligencia por esfuerzos solitarios y requiere la formación de comunidad y el esfuerzo compartido de investigadores, universidades y naciones en esta prospectiva.

\section{Un camino histórico hermenéutico}

La indagación que soporta este escrito es cualitativa, su problema es la identificación de los factores subyacentes de la contabilidad en América Latina, en su tránsito de la etno-contabilidad a los desarrollos actuales, generalmente filtrados por colonizaciones contables, primero del enfoque continental europeo y luego por la influencia anglosajona. El método de indagación se basa en la hermenéutica, incorporando aspectos específicos que van desde los preconceptos del autor al conocimiento de la cosa misma en su horizonte de tradición que recoge las experiencias vividas en su desarrollo, incorporando análisis exegéticos, interpretación lógica e histórica, con el fin de develar los orígenes y progresos de las tradiciones identificadas como consecuencia de la existencia de concepciones opuestas sobre la naturaleza, objeto y método de la contabilidad. Ello requiere la ubicación histórica del problema y su génesis, interpretando críticamente los desarrollos positivos y normativos de la contabilidad, así como los estudios realizados por el subjetivismo epistemológico.

Estos elementos del horizonte de experiencia y tradición se confrontan con un horizonte de perspectivas ligado a una teoría general de la contabilidad y las concepciones contamétricas (Franco, 1998, pp. 242-251)

Las fuentes de información son bibliográficas y se constituyen por textos relacionados con el problema tradicional del enfoque monológico (Balboa, Piedra, \& Margarita, 2002) de la contabilidad, abordándolo no en una condición estática sino en su proceso evolutivo y en segundo lugar por formulaciones teóricas relacionadas con los conceptos y su función en el problema estudiado, dentro de la teoría contable. Esto no hubiera sido posible sin abordar, aunque de manera incipiente, los fundamentos filosóficos y epistemológicos que respaldan los argumentos de desarrollo y alternativas del conocimiento contable, en su camino a estructuras heteroglósicas, como se puede argumentar con base en el pensamiento pragmático norteamericano e incluso desde la teoría literaria (Baker, 2011).

Esa fusión de horizontes se desarrolla en el proceso histórico y permite la construcción de textos o estructuras textuales que denotan la interpretación de las afirmaciones de las diferentes escuelas, es decir se sigue el circulo comprensivo (Gadamer, 1999, pp. 331 587) que soporta a la hermenéutica como método.

Develar el origen y efecto de los factores de estancamiento del conocimiento contable y formular una alternativa de solución de carácter multidimensional y heteroglósico, constituye el objetivo de este trabajo, logrando fundamentar el concepto de contametría como tecnología contable, para contribuir al proceso de clarificación de los constructos contables y avanzar en la formación epistemológica de la disciplina. 


\section{¿Existe un pensamiento contable latinoamericano?}

La pregunta parece trivial, el nombre de América Latina deviene de un proceso de colonización, haciendo referencia a aquellas regiones que adoptaron como lenguas algunas de las llamadas lenguas romances, de tronco latino como es el caso del castellano (el más hablado) el francés y el portugués. En tal circunstancia y considerando que el proceso de colonización conformó la destrucción de la cultura aborigen la cultura contable de esta región va estar ligada, al menos en principio a la de sus colonizadores. De la cultura contable precolombina solo quedan registros arqueológicos de una etno-contabilidad sobre la cual procede recordar algunos rasgos que pueden constituir interés para efectos investigativos.

Cuando en 1492 las expediciones espańolas, buscando una nueva ruta comercial con las Indias Orientales, pisaron tierra americana, encontraron en ella una población indígena de cultura avanzada, con complejas organizaciones políticas, económicas y religiosas. Tribus sedentarias, dedicadas especialmente a la agricultura y con numerosa población (Franco, 2011, p. 184). Manifiestan algunos autores que estas tribus americanas, se encontraban en la etapa prehistórica del desarrollo de la humanidad, con las características inherentes a la barbarie, aunque con rasgos distintos de esta época de desarrollo en el viejo mundo, en razón de que allí se dio la domesticación y cría de animales por cuanto poseían casi todos los domesticables, mientras que América no tenía más mamíferos que la llama, en una parte del sur del continente y sólo uno de los cereales cultivables, pero el mejor, el maíz (Engels, 1982) .

Siendo las tribus americanas, atrasadas en su desarrollo (algunos estaban incluso en etapa de salvajismo), no se encontraban desarrollados completamente los elementos necesarios para la existencia de la contabilidad, no se conocía escritura alfabética. Sin embargo cuando llegaron los españoles la contabilidad era una práctica normal en América (Franco, 2011, p. 184). Pero esta condición reafirma la tesis de que la contabilidad precedió a la aritmética y la escritura (Besserat, 2004), dado que se incorporaron elementos de cualidad y cantidad en sus prácticas, los mismos elementos de las cuentas.

Las más importantes comunidades aborígenes, integrantes de una cultura originaria de un lugar que ya no es la dominante, desarrollaron sistemas de cuantificación clasificadas por los investigadores como desarrolladas a pesar de que se soportaran sobre figuraciones por la ausencia de la escritura como en el caso de los incas o con algún soporte escritural como sucedió con los mayas, los aztecas y los muiscas.

Los sistemas de numeración figurada utilizan marcas sobre elementos físicos (Fedriani \& Tenorio, 2004) como es el caso de los incas con su técnica de Quipus. Los sistemas de cuantificación hablada designan nombres para cada cantidad y carecen de referentes figurativos o escritos, mientras los sistemas escritos utilizan símbolos existentes o emergentes para designar cifras (Fedriani \& Tenorio, 2004). 
Tabla 1. Sistemas de cuantificación

\begin{tabular}{llll}
\hline \multirow{2}{*}{$\begin{array}{c}\text { Clases } \\
\text { de interpretación }\end{array}$} & \multicolumn{3}{c}{ Tipos de representación } \\
\cline { 2 - 4 } Aditivo & Figurativo & Hablado & \multicolumn{1}{c}{ Escrito } \\
Hibrido & Terciario, Cuaternario & & $\begin{array}{l}\text { Vigesimal } \\
\text { (Mayas, Aztecas) }\end{array}$ \\
Posicional & & \\
\hline
\end{tabular}

Fuente: Construcción del autor con base en (Fedriani \& Tenorio, 2004).

La segunda dimensión de los sistemas de cuantificación se constituye por unas reglas de interpretación y es propia de los sistemas escritos, lo cual no quiere decir alfabético, y se clasifican en sistemas aditivos, híbridos y posicionales (Fedriani \& Tenorio, 2004). Los sistemas aditivos permiten realizar operaciones aritméticas de sumas y restas para componer los números a partir de las cifras mientras los sistemas híbridos incorporan la multiplicación y potenciación para componer y los sistemas posicionales utilizan cifras representadas por signos que compondrán números de acuerdo a la posición donde se les ubique (Fedriani \& Tenorio, 2004). En la tabla 1 se muestra la clasificación de los sistemas de cuantificación sobre los cuales se soportaba la contabilidad de las principales comunidades aborígenes de América Latina.

En sus prácticas contables los aztecas hacían cálculo y cuenta de los tributos que imponían a los pueblos sojuzgados (Franco, 2011, p. 184). "... los mayordomos derramaban los tributos, los recogían y los distribuían por cuenta; conocían el efectivo de los ejércitos en guarnición y en campaña y les preparaban vestidos y raciones; partían ciertas rentas entre los sacerdotes, el culto y la fábrica del Teocali” (Gertz, 1976). Ellos utilizaron unos símbolos para representar algunas cifras, según han encontrado los investigadores en el Codex Mendoza, el punto o mancha para el uno, la bandera o hacha para el veinte el maíz para el cuatrocientos y la muñeca de maíz para el ocho mil; para los números intermedios utilizaron los dedos de la mano (2,3 y 4 ), la mano (5 y 10), el pie (15) y el hombre (20) (Fedriani \& Tenorio, 2004). Existen indicios de que el sistema azteca no sea aditivo sino híbrido, dado que si se coloca un hombre debajo de una mano se hace referencia a cien hombres, es decir hay una multiplicación.

Los sistemas de cuantificación de los mayas son más avanzados, algunos lo consideran el más avanzado y también se clasifica aditivo escrito. Los mayas ocuparon los territorios de Mesoamérica, es decir México, Guatemala, el Salvador, Honduras y otras culturas del sector. Construyeron un sistema de doble base, quinaria y vigesimal siendo prevalente la segunda; uno de los elementos más importantes de su sistema es la inclusión del cero (Barrios, 2015, p. 44), que desde siempre se ha considerado una invención india, 
ellos lo representaban con un óvalo o concha y forma parte de la comprensión de los números. Utilizaron un sistema de puntos y líneas, los primeros se usan para cuantificar de uno a cuatro y las líneas horizontales significan cinco; líneas con puntos encima se suman como se afirma en diferentes Codex como Dresde, Paris y Madrid (Fedriani \& Tenorio, 2004). Al igual que el sistema azteca, el maya evidencia ser híbrido dado que la comprensión de las cifras incorpora multiplicaciones y potenciaciones.

El sistema maya de cuantificación está ligado a su cosmología y se combinaron con figuras antropomorfas para representar veinte deidades con su calendario de origen, algo referente a sus conmemoraciones. Igualmente incorporaron en sus mediciones dos calendarios, uno de 260 días que se determinaron como el producto de trece deidades por veinte días, una especie de tarot u horóscopo y otro de trescientos sesenta y cinco días relacionados con la traslación del sol (o de la tierra) con un día adicional cada cuatro ańos, dato sorprendente por la precisión si se relaciona con los actuales estudios al respecto (Fedriani \& Tenorio, 2004). Esta combinación permitió controlar el consumo de cosechas y productos, una importante función de la contabilidad.

La cultura Inca es la de mayor importancia por su población y extensión, su territorio comprendió desde los Andes argentinos hasta el sur de Colombia. "El Inca no acude a signos escritos pero maneja notablemente sus cuentas mediante lo que llamó "Quipus", que consiste en cuerdas con múltiples nudos en colores, mucho sirvieron al pueblo, que alcanzó civilización muy notable" (Gertz, 1976). El sistema se integra por cinco tipos de cuerdas, principal, colgantes, superiores, colgante final y secundarias y auxiliares (Fedriani \& Tenorio, 2004). Su sistema de cuantificación es decimal, pero con una base binaria, línea y nudo, constituyó un sistema escritural más allá de los números. El sistema es complejo porque incorpora diferentes signos, como los colores que representaban factores diferenciales como ubicaciones geográficas, tribus, clase de productos; una cuerda superior se utiliza para agrupar cuerdas colgantes representando una característica especial de los elementos representados en estas (Fedriani \& Tenorio, 2004).

Para la realización de cálculos los incas utilizaron una tableta conocida como Yupana, en la cual se traza una matriz de cinco filas por cuatro columnas; las columnas, vistas de derecha a izquierda tienen en sus celdas la misma información, 1, 2 .3 y cinco, mediante puntos, es decir los primeros números primos y se cree que las filas de abajo hacia arriba tenia valores de uno, 10, 10 al cuadrado, diez al cubo y diez a la cuatro. Al yupana se le ha dado en llamar ábaco inca por su potencia para realizar cálculos incorporando posiciones, adiciones, multiplicaciones y potenciaciones. La comunicación de datos es otro elemento de la contabilidad inca, el traslado de las cuentas hacia centros de decisión se realiza a buena velocidad mediante la actividad de los chasquis, corredores de relevos, ubicados en centros de relevo, (Fedriani \& Tenorio, 2004) situados aproximadamente a dos kilómetros de distancia. Su acción rápida permite la transmisión de información con "celeridad"

En cuanto a los desarrollos de la contabilidad en Colombia la información más conocida es relativa a los muiscas, una organización social de la cultura y lengua chibcha 
que integró nueve tribus, tayronas, cunas, tunebos, gorrones, paeces, guambianos, quilacingas, pastos además de los muiscas. Estos últimos ocuparon los territorios de Boyacá y Cundinamarca actuales, fundamentaron su comercio en la sal y llegaron a utilizar como moneda discos de oro. "En cuanto se refiere a la civilización Chibcha, el comercio es escaso. Es dado por un intercambio de productos dentro de las tribus de una misma confederación. (Asociación de Tribus de características similares) y por otra parte, para cambiar productos con tribus forasteras.

El control del intercambio, trueque, está dado por un sistema numérico para contar las unidades intercambiadas. Este sistema se expresa en grupos de veinte objetos y si se necesitaba contar por cantidades mayores se multiplicaba este número las veces necesarias. El registro que se hacía de ello se daba en pigmentaciones sobre la túnica del encargado de este menester" (Díaz, 1980). Las cifras de uno a veinte se representaban mediante pictografías de lunas y medias lunas; nuevamente aparece la posibilidad se sistemas híbridos por la presencia de la multiplicación en la comprensión de los números. En la cultura Quimbaya de hábiles orfebres se desarrollaron algunos elementos de gran importancia en el desarrollo de la contabilidad. "Y a fin de que el intercambio de productos, fuera un cambio entre iguales, esta experiencia (el dibujo cuantificado) permitió la elaboración de tablas de equivalencia para agilizar el mismo intercambio (Comunidad de los quimbaya) (Ariza, 1976).

Se observa que las comunidades indígenas americanas utilizaban métodos contables superados desde tiempos inmemoriales por las culturas del viejo mundo, especialmente Europa. Sus transacciones comerciales, corresponden a las primeras formas de intercambio, originadas por la producción de excedentes, entre tribus, es decir la propiedad es común, a pesar de que se presenta la figura del administrador y una forma de Estado que señala el tránsito a la civilización, hacia la propiedad privada, que encarna la figura de los caciques, jefes que se apropian sinnúmero de privilegios. La contabilidad en este medio demuestra una vez más la invalidez de criterios impartidos, en el sentido de que ella no es posible sin la existencia de la moneda como patrón de medida (Franco, 2011, p. 185).

\section{Las colonizaciones contables de América Latina}

Los desarrollos contables autóctonos fueron arrasados por procesos de colonización a finales del siglo XV. El mayor colonizador fue España que ocupó el sur de Norteamérica, Mesoamérica, la región andina de sur-américa y el valle del Rio de la Plata, Así como los territorios de Paraguay, llegando por el rio del mismo nombre, es decir los territorios de las más importantes comunidades aborígenes. En segundo lugar se ubica Portugal que ocupó América del sur por el Atlántico controlando todo el territorio actual de Brasil y el tercer colonizador es Francia que ocupo territorios de Quebec y Montreal en Canadá, la Guayana francesa y algunos territorios del caribe, entre ellos parte de la Isla la Espańola que hoy constituye el territorio de Haití. 
El proceso de colonización sustituyó la lengua, la religión y otros elementos de la cultura, al tiempo que generó intercambio de enfermedades (trajeron la viruela y el sarampión y llevaron la sífilis) y originó cambios en la economía por la traída de especies agropecuarias y estructuras fiscales que se combinarían con las nativas, pero especialmente sustituyeron la contabilidad local que prácticamente desapareció, siendo sustituida por la contabilidad italiana que predominaba en las naciones conquistadoras.

\section{La primera colonización}

Los colonizadores impusieron su cultura en las colonias y en ese contexto, las costumbres mercantiles y prácticas contables italianas. El descubrimiento de América, acaece en momentos en que Europa transforma sus relaciones de producción, cuando el feudalismo da paso al triunfante mercantilismo característico del primer capitalismo. España queda ausente de este proceso, por los efectos negativos de los tesoros americanos, así como por la derrota de la burguesía nacional en la batalla de Villalar, a manos del monarca Carlos V en el año 1531. Posteriormente Felipe II decretó la expulsión de los moros y los judíos de España, sectores éstos que constituían las fuerzas fundamentales de la agricultura y el comercio. Con estos acontecimientos Espańa se constituye en el país más estancado de Europa, en lo económico y genera las condiciones de negación al avance del pensamiento (Franco, 2011, pp. 187-188).

Antes de estas circunstancias mencionadas, España estuvo abierta a los pensamientos y conocimientos generados en Europa, como se muestra en la organización de las cuentas reales, ordenadas por Alfonso el Sabio en 1263, cuando impuso a los funcionarios encargados de la administración de las rentas públicas, la obligación de rendir cuentas anuales, práctica que se normalizó totalmente en 1436, cuando la función de tomar las cuentas a los administradores y recaudadores recayó en persona de los oidores de la Real Audiencia; en 1476 se emitieron ordenanzas reales para establecer claramente la forma de rendición de las cuentas. (Franco, 2011, p. 188)

Esta organización contable es trasladada a América a partir de la propia conquista; en 1519 al iniciarse la conquista de México por Hernán Cortés se fundó el ayuntamiento de Veracruz, eligiendo como contador a don Alfonso de Ávila. "El 15 de octubre de 1522, Carlos V, al tener noticia de la consolidación de la conquista de la Nueva España, emite en Valladolid una cédula real en la que se ordena: Acatando a la suficiencia y habilidad de vos, Rodrigo de Albornoz, nuestro secretario y los servicios que nos habéis hecho; y porque entendemos que a nuestro servicio cumple y a la buena guarda y mando de nuestra hacienda, es nuestra merced que ahora y de aquí en adelante por el tiempo que nuestra voluntad fuere, seáis nuestro contador en la dicha tierra". Juntamente con su nombramiento de Contador Real, don Rodrigo de Albornoz recibió también una cédula de instrucción que es el punto de partida de los muy elaborados reglamentos de la contabilidad fiscal de la Nueva España” (Gertz, 1976). 
"En la cédula mencionada se le instruye acerca de la forma en que se deben registrar las operaciones en el Libro Grande que para ello os mando que tengáis, de manera que de todo haya muy larga cuenta e verdadera e clara relación", se ordena al mismo tiempo, que para evitar discrepancias, todas las partidas que se registran vayan firmadas por el contador y por el tesorero, principio fundamental de control que habría de perdurar a través de los años" (Gertz, 1976).

Resulta importante determinar de qué prácticas contables se estaban estableciendo reglas y ello conduce a reconocer que las mismas correspondían al concepto de contabilidad forense, es decir contabilidad como proceso de construcción de pruebas judiciales, consecuencia de la generalización de la herencia romana que tuvo un énfasis más jurídico que técnico en razón de las dificultades de operación de su sistema de numeración y la ausencia del cero en la misma. El enfoque contable italiano se reconoce generalmente como Cuenta y Razón y se desarrolla básicamente por tres sistemas: Data y recibo, Cargo y data y Cargo y descargo más conocido como partida doble.

El sistema de Cargo y recibo consistía en el uso de dos hojas, una para registrar lo que se recibía y otra para registrar lo que se entregaba en relación con cada transacción y en general se reconoce como una aplicación de partida simple. El sistema de Cargo y data se utilizó para soportar la rendición de cuentas por parte de los responsables del manejo de un recurso y también se considera una práctica de partida simple en la que se registra lo recibido para tutelar y las salidas y gastos que requiere tal tutela para establecer los bienes a reintegrar en fechas predeterminadas, normalmente en junio y diciembre. El sistema de cargo y descargo o partida doble es utilizado para informar sobre las empresas o entidades e incorpora la gran novedad de cuentas nominales y reales y solo se establece en 1551, cuando “...el Rey Felipe II por cédula real ordena llevar la contabilidad del Reino por partida doble, lo que señala la influencia, aunque tardía, de la contabilidad italiana en España" (Franco, 2011, p. 189).

Se estableció en las colonias un régimen fiscal integrado por diversos impuestos para cuya percepción existieron dos sistemas: Recaudación y administración directa por parte del Estado y adjudicación por remate a particulares, los cuales eran responsables por su manejo y disposición. “... Precisamente, Antonio Nariño, quién era recaudador de ellos, incurrió en un desfalco al no poder presentar los dineros confiados a su custodia en el momento en que se le exigían. Sin embargo, para juzgar su conducta hay que tener en cuenta las prácticas y costumbres de la época que autorizaba a los que habían rematado la recaudación para negociar con los dineros percibidos hasta entregarlos en una fecha determinada. Nariño, que había traducido Los Derechos Del Hombre, fue acusado políticamente y obligado en lo inmediato a restituir los fondos antes de la fecha de vencimiento de su cargo, con la consecuencia de que resultó fallido, no obstante que los créditos a su favor, los cuales aspiraba a hacer efectivos antes de la fecha fijada para la rendición de cuentas, eran superiores a la suma adeudada al tesoro" (Tirado, 1976). Narińo fue nuevamente juzgado por esta circunstancia por el parlamento en la época republicana y su defensa 
es un tratado de contabilidad de carga y data (Suarez \& Franco, 2017, pp. 117-144). El método todavía se usa en control fiscal.

El método de cargo y data incorporó cuatro pasos a saber: Examen de justificantes, Verificación de cifras, Pago del saldo y Liquidación de la cuenta (Villulenga de Gracia, 2013). El proceso parece establecido sobre el examen de la cuenta rendida y no sobre la rendición de la cuenta y señala que se verifican los soportes de los movimientos, se verifican las cifras que de ellos se derivan, se reciben los reintegros cuando a ello hay lugar y finalmente se expide el finiquito sobre la cuenta que constituye una cesación de responsabilidad o en contrario se establece el alcance de la responsabilidad por faltantes.

En España, "La sustitución del cargo y data por la partida doble es considerada por los investigadores como el paso de la tradición a la modernidad contable...” (Villulenga de Gracia, 2013). En el caso de España la adopción de la partida doble no solo fue tardía, luego de la cédula real de Felipe II en 1552 el asunto entró en olvido, al tiempo que el reino entraba en una crisis del comercio y solo renacieron las preocupaciones en el siglo XVIII en especial por las Ordenanzas de Bilbao en 1737 y luego en 1762 por su incorporación a la administración de las Haciendas y la formulación de manuales de aplicación que generarían gran difusión y aceptación desde la reincorporación al poder de los Borbones (Donoso, 2003), La reforma no solo se establece para las instituciones españolas sino para la nueva España, las colonias en América y solo entonces se consolida la primera colonización contable de América Latina.

\section{Segunda colonización}

La extensa descripción de la primera colonización resulto necesaria, de alguna manera sus productos de origen latino también fueron asimilados por los nacientes enfoques anglosajones de la contabilidad, los cuales aportarían una diferencia sustancial en relación con el control, dado el carácter posterior de la auditoría y su énfasis en información financiera, a diferencia del enfoque latino de control permanente y énfasis en las transacciones (Franco, 2012, pp. 53-109). La primera colonización tuvo efectos que trascendieron la colonización económica y política y alcanzó hasta comienzos del siglo XX cuando surge un nuevo hegémono como consecuencia de la primera guerra mundial, Estados Unidos de América.

Esta segunda colonización tiene origen en la estructura de los mercados profesionales fuertemente concentrados en un pequeño grupo de firmas multinacionales. Estas firmas requieren estandarizar los procesos contables a nivel global para lograr altos rendimientos en cualquier lugar del mundo, requisito para la concentración de los mercados y por ello inician un proceso internacional de regulación a partir de las primeras décadas del siglo XX, pasando de la regulación conceptual a la obligación legal (Franco \& Alvarez, 1988, pp. 1-5). Estas firmas se instalan mediante diversas estrategias en los mercados profesionales de América Latina a partir de la década de 1920. 
Esta regulación no es expresión de iniciativas pioneras o inquietudes creadoras, comporta un aire universal que recorre el mundo occidental, con aceleramientos en periodos de crisis como en el caso del colapso de la Bolsa de Valores de Nueva York, incorporando en su desarrollo a países de economías emergentes, en especial África y América Latina (Franco, 1998, p. 47). El aire regulador no es una expresión humanística o técnica de la profesión para homogeneizar una práctica o un lenguaje especializado, es un proceso de integración de pirámides de poder derivada de una concepción social más amplia, la arquitectura social de la comunidad empresarial (Franco, 1998, p. 47) que ha fijado un código de convivencia orientado a la optimización de la productividad y la competitividad integrado por los principios de uniformización, especialización, sincronización, concentración, maximización y centralización (Tofler, 1980).

La producción simbólica se concentra en el Instituto Americano de Contadores Públicos Autorizados (AICPA por sus iniciales en inglés) que inicia un proceso de construcción de normas en 1917 con la emisión del "Uniform Accounting" que sería objeto de nuevas versiones y bajo nuevos nombres en 1918 y 1929, que alimenta la producción de textos incorporados a los procesos educativos, medio especial de la segunda colonización, para luego convertirse en contenido de propuestas de regulación legal en el ámbito latinoamericano, en especial a partir de la década de 1940 (Franco, 1998, pp. 80-84). Esta etapa de la colonización puede denominarse la General Aceptación y desarrollo un modelo contable instrumental, sobre las bases de la partida doble, mediante una metodología de inventario de las prácticas más aplicadas por profesionales en Estados Unidos, con base en las cuales se estableció un modelo conceptual lógico estructurado en diez postulados, cinco objetivos y treinta y dos principios (AICPA, 1965), consecuencia del Estudio de Investigación Contable Siete (ARS-7) bajo la dirección de Paul Grady, fuertemente influido por las firmas contables que lo constituyeron siempre en su saber hacer (Franco, 2011, pp. 75-94).

Este proceso de colonización que mezcla como medios, la educación, la regulación y el monopolio de mercado se conecta con la estrategia del capital a partir de la segunda guerra mundial conocida como la Teoría del Régimen Internacional (Franco, 2013 A) de la mano del Comité de Cooperación Contable Internacional creado en 1961. Puede afirmarse que la segunda colonización se orientó a la uniformización instrumental en las prácticas contables para facilitar la concentración de los mercados a nivel internacional.

\section{La tercera colonización}

Esta tercera experiencia de colonización contable de América Latina se desarrolla mediante la segunda aplicación de la teoría del Régimen Internacional en contabilidad a partir de la década de 1970, con la conformación de organismos internacionales de regulación como IASC e IFAC, el apoyo de instituciones multilaterales como el Fondo Monetario Internacional y el Banco Mundial y el proceso de privatización y desprofe- 
sionalización de la regulación contable que toma dimensiones amplias, extendiéndose a asuntos como la auditoría, la ética, la educación, la contabilidad estatal, la calidad de servicios profesionales y hasta los contratos de aseguramiento en la prestación de servicios profesionales (Franco, $2013 \mathrm{~A}$ ) .

El proceso se inicia en Estados Unidos con la sustitución de los órganos de regulación de AICPA y de este mismo como sujeto activo de la regulación, mediante la creación de la Fundación para la Contabilidad Financiera (FAF por sus iniciales en inglés) cuyos benefactores que designan a los fideicomisarios son grandes empresas de diversas actividades económicas. La junta de benefactores designa a los integrantes del nuevo regulador, el Consejo de Estándares de Contabilidad Financiera (FASB por sus iniciales en inglés) cuyas decisiones son avaladas por la Comisión de Valores y Cambio (SEC por sus iniciales en inglés) para la conformación de los Principios de Contabilidad de General Aceptación en Estados Unidos (USGAAP) (Franco, 1998, pp. 84-88).

La tercera colonización incorpora grandes transformaciones en la contabilidad siendo la primera el abandono de la función de rendición de cuentas y medición del beneficio verdadero que a ella subyace para apoyarse en la gerencia del valor, característica de una economía financiarizada, construyendo un adiós a la verdad objetiva para transformar la contabilidad en representación de verdades subjetivas, esta deja de ser atributo del objeto de representación y se funda en el sujeto que valora. El costo histórico cede su sitial al valor razonable, las transacciones dejan de ser las únicas fuentes de los recursos que ahora pueden construirse por la nueva valoración, la contabilidad pierde el carácter de bien público mundial y se transforma en mercancía de uso determinante en el funcionamiento de los mercados de capitales y en especial los dedicados a los valores (Franco, $2013 \mathrm{~A}$ ).

Una segunda característica de esta colonización es la pérdida de función forense de la contabilidad, la cual es abandonada en su consideración como proceso y la sustitución por una regulación para la presentación de estados financieros de propósito general y su consecuente aseguramiento; no hay contabilidad, hay información.

Europa no aceptó que el mundo funcionara con base en regulación estadounidense e inició su propio desarrollo (Cook, 1988) coadyuvando a la creación de un organismo de origen gremial, Comité de Estándares Internacionales de Contabilidad (IASC por sus iniciales en inglés) que inicia su propia dinámica de emisión de Estándares Internacionales de Contabilidad (IAS por sus iniciales en inglés), las cuales encuentran amplio reconocimiento profesional e institucional en especial por la Comunidad Económica Europea que evolucionaría a Unión Europea.

Pero la iniciativa de regulación internacional no puede abstraerse de la nueva realidad geopolítica que determina que la soberanía reside en las empresas y los estados se constituyen en instituciones para su desarrollo, iniciando un proceso de transformación institucional mediante la creación de una fundación que actualmente tiene el nombre de IFRS Foundation que se encarga entre otras funciones de designar los integrantes del consejo regulador International Accounting Standard Board (IASB) que inicia la emisión 
de una nueva serie de estándares International Financial Report Standard (IFRS), cambio de nombre que informa el abandono de las preocupaciones contables y el interés por la información financiera, una adhesión a la postura y estructura estadounidense que se profundiza en el desarrollo de Acuerdo de Norwalk que determinó su convergencia hacia una regulación global única (Franco, 2013 A).

La nueva regulación no emite estándares, proporciona alternativas distintas de reconocimiento de los mismos hechos, ni son de contabilidad porque se refieren a información financiera. Constituyen un menú para preparación de los informes al gusto de los usuarios, oferentes y demandantes de productos en los mercados de capitales, la información es mercancía de calidad. En el entorno global se determina que esta regulación debe ser adoptada por todas las naciones, una expresión de colonización global.

\section{Las resistencias, escuelas autónomas de pensamiento}

Las colonizaciones contables han sido aceptadas en América Latina y apalancadas por diversos organismos regionales como el Banco Interamericano de Desarrollo, organizaciones gremiales como la Asociación Interamericana de Contabilidad (Morales, 2006), organismos profesionales nacionales vinculados a International Federation Accounting Certificied (IFAC), que constituyen el aparato institucional de la colonización. Igualmente, investigadores adheridos a estas líneas de pensamiento se lamentan de los problemas que obstaculizan la pronta colonización y añoran mayor trabajo investigativo para alcanzar las fronteras de conocimiento del pensamiento contable anglosajón (Macias \& Moncada, 2011).

Frente a estas concepciones América Latina desde orillas alternativas trabaja en la construcción de una identidad propia, partiendo del desarrollo del pensamiento crítico interpretativo o profundizando en escuelas latinas fundadoras de importantes construcciones teóricas (Masi, 1962) (Masi, 1943). Surgen así pensamientos alternativos que en general buscan el desarrollo de la contabilidad como disciplina, antes que como artefacto regulativo.

\section{La teoría neo patrimonialista}

El neo patrimonialismo es una construcción teórica que desarrolla los conceptos de la escuela italiana patrimonialista expuesta en sus niveles más avanzados por Vincenzo Masi (1893-1977) que continuo el trabajo de Fabio Besta (1845-1922) quién había expuesto una teoría de la representación de los elementos del patrimonio, abriendo un camino al conocimiento del patrimonio de la Azienda que constituiría el objeto de estudio de la contabilidad, insistiendo en que la gran problemática se resolvería construyendo una definición de contabilidad sobre lo cual Gino Zappa (1879-1960) consideró que existía inmadurez para realizarla, frustrando las iniciativas del maestro (Masi, 1962, pp. 5-6). 
Masi se separó de los pensamientos de Zappa para quien la contabilidad se reducía a la representación de la Azienda, dando gran importancia a la economía aziendale, optando por la contabilidad como ciencia de los fenómenos patrimoniales, con lo cual la contabilidad se dignifica como ciencia, amplía sus tareas encontrando inagotables problemas por resolver, superando los niveles instrumentales y la simple representación (Masi, 1962, pp. 35-43).

El trabajo científico de Masi es continuado en América Latina por el profesor Antonio Lopes de Sá (1927-2010), un pensador influyente que funda la escuela neo-patrimonialista llevando la clásica teoría a niveles más avanzados en el campo social preocupándose más por la eficacia social del patrimonio que por su propiedad, dedicando toda su vida a fundamentar las bases epistemológicas de una teoría general del conocimiento contable, dentro de unas perspectivas éticas. "Con justicia puede decirse de él que fue por antonomasia un verdadero filósofo de la contabilidad" (Suarez, 2014). Su trabajo intelectual le permitió la publicación de 183 libros y cerca de 13.000 artículos científicos publicados en revistas especializadas de todo el mundo, haciéndose acreedor de múltiples reconocimientos. Treinta días antes de morir, con la plena lucidez que toda la vida lo acompañó, dijo en una conferencia que siempre buscó socializar el conocimiento, difundir la ética y el respeto por el prójimo (Suarez, 2014). El trabajo encuentra continuidad con una perspectiva crítica, cultural e histórica en pensadores de dinámica producción y gran aporte constructivo (Nepomuceno, 2008).

"El profesor Lopes de Sá fue autor de muchas teorías originales de naturaleza científica, escritas en varios idiomas y reconocidas por sus valiosos aportes al conocimiento contable: teoría del equilibrio de capital, teoría de los cocientes derivados y de las correlaciones, teoría de la liquidez dinámica, teoría de las funciones sistemáticas del patrimonio, teoría de la prosperidad y teoría de las interacciones sistemáticas de las funciones patrimoniales" (Suarez, 2014).

Este eximio autor balanceo los problemas de función y posesión de la riqueza concluyendo que lo determinante en la contabilidad es la función y esta se construye, mide y representa mediante el concepto de eficacia social, la cual se entiende como la capacidad de realizar los ofrecimientos de la riqueza para la satisfacción de necesidades o para satisfacer fines que postula no deben limitarse a los empresariales reducidos a la reproducción del patrimonio sino a su dimensión social.

Lopes de Sá confrontó las bases de las escuelas anglosajonas de contabilidad por sus métodos fundamentados en consensos de grupos de poder y su lógica empírica e instrumental para dar cuenta de la riqueza individualizada, muy ligada a los intereses del capital y de las firmas multinacionales de auditoría; reivindicó el neo-patrimonialismo como una escuela de origen brasilero según la cual la contabilidad cuenta con una teoría general apoyada en axiomas, teoremas y metodologías propias. La teoría contable no puede construirse por casuística, ni fundamentarse en curiosidad subjetiva, en observaciones 
cotidianas, requiere un rigor metodológico que incorpore las lógicas de la necesidad, de la finalidad, del patrimonio medio, de las funciones patrimoniales y de las interacciones funcionales que alimentan la Teoría de las Funciones Sistémicas del Patrimonio (Lopes de Sa, 2003).

La teoría general de la contabilidad formulada por Lopes de Sá incorpora una serie de elementos relacionados con las funciones patrimoniales, como la consideración de sistema abierto que reconoce que los hechos exógenos al patrimonio influyen en su comportamiento y debe inspirar acción humana, sin descuidar los fenómenos endógenos que tienen los mismos efectos y por tanto se establece una armonía entre el patrimonio y los factores endógenos y exógenos. La eficacia social es el elemento básico del funcionamiento armónico y se procesa mediante las funciones sistemáticas del patrimonio considerando los efectos en los sistemas de funciones que deben acompañar las relaciones lógicas involucradas en campos integrales de comportamiento. Cuando las necesidades patrimoniales son satisfechas las finalidades se cumplen, la eficacia se realiza y se genera superación o desarrollo social, dado que lo patrimonial y social constituyen un universo formado por sistemas de funciones estructurados en sus componentes que cumplen diversas funciones teniendo como meta la eficacia (Lopes de Sa, 1992, pp. 257-258).

La teoría general del conocimiento contable es estructurada a través la teoría de las funciones sistemáticas del patrimonio (Lopes de Sa, 1990) ${ }^{1}$ en las que se establece una relación entre sistemas de necesidades patrimoniales y relaciones lógicas a partir de la prevalencia sobre la función de los medios patrimoniales que conducen a la eficacia que de la posesión o propiedad de los mismos, lo que ofrece la riqueza antes de lo que se tiene de riqueza. Esta teoría se construye a partir del reconocimiento de elementos fundamentales como son los componentes que integran el patrimonio medio y el patrimonio necesidad, el tiempo, el espacio y la resultante, variables estas que soportan la construcción de axiomas y teoremas explicativos y predictivos de la contabilidad (Lopes de Sa, 1990).

Con base en los elementos o variables enunciados se determinan los componentes del sistema de funciones sistemáticas del patrimonio integrados por relaciones lógicas y sistemas de necesidades y funciones que permiten establecer relaciones funcionales orientadas a la obtención de unas capacidades a cada sistema de necesidades o funciones.

Las relaciones lógicas se clasifican en esenciales, dimensionales y ambientales: las primeras definen la naturaleza de la relación y se refieren a necesidades, finalidades, medios y capacidades características del patrimonio en aspectos relacionados con sus medios y funciones. Las relaciones lógicas dimensionales se refieren a los problemas de medición e incorporan variables de causa/efecto, tiempo, espacio, calidad y cantidad, en la consideración de la causa y el patrimonio medio y efecto en el patrimonio necesidad en los sistemas de funciones y necesidades. Finalmente la relación lógica ambiental que aborda el conocimiento de las influencias de los factores endógenos en aspectos institucionales,

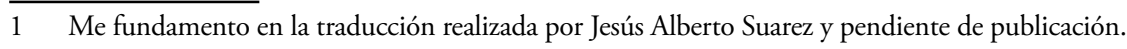


psíquicos y espontáneos, así como factores exógenos en aspectos ecológicos, legales, fiscales, científicos y tecnológicos.

Tabla 2. Teoría de las funciones sistemáticas del patrimonio

\begin{tabular}{|c|c|c|c|c|}
\hline \multirow{2}{*}{$\begin{array}{c}\text { Sistemas } \\
\text { de funciones } \\
\text { y necesidades }\end{array}$} & \multicolumn{3}{|c|}{ Relaciones lógicas } & \multirow[b]{2}{*}{ Capacidad } \\
\hline & $\begin{array}{c}\text { Esenciales } \\
\text { (naturaleza) }\end{array}$ & $\begin{array}{l}\text { Dimensionales } \\
\text { (medición) }\end{array}$ & $\begin{array}{l}\text { Ambientales } \\
\text { (influencias) }\end{array}$ & \\
\hline Liquidez & & & & Capacidad de pago \\
\hline Resultabilidad & & & & Disfrute del patrimonio \\
\hline Productividad & & & & Eficiencia de medios \\
\hline Elasticidad & & & & Equilibrio patrimonial \\
\hline Estabilidad & & & & $\begin{array}{l}\text { Dimensionamiento } \\
\text { patrimonial exógeno }\end{array}$ \\
\hline Invulnerabilidad & & & & Protección contra el riesgo \\
\hline Economicidad & & & & Perdurabilidad \\
\hline
\end{tabular}

Fuente: Construcción propia con base en Lopes de Sá, Teoría de las funciones sistemáticas del patrimonio.

En el neo patrimonialismo lo lógico prevalece sobre lo instrumental y por ello su compromiso es con la generalidad. Se aborda el estudio de las causas y su relación con el objeto y su finalidad (Coelho da Rocha, 2004) en un entorno de ontología objetiva y subjetiva y una epistemología objetiva.

"Cuando la suma de la eficacia de todos los patrimonios implique la suma de la eficacia de todas las células sociales, en régimen de armónica interacción, eso implicará, lógicamente, la eficacia social, lo que equivaldría a la anulación de las necesidades materiales de la humanidad" (Lopes de Sa, 1992, p. 258)

\section{Pretensión de una teoría general de la contabilidad}

Una segunda gran experiencia de desarrollo de pensamiento contable en América Latina corresponde a la adelantada por el profesor Carlos Luis García Casella en Argentina, quién a diferencia de Lopes de Sá no parte de la escuela latina, lo hace de la escuela anglosajona y puede asegurar que a partir de la crítica al trabajo de Mattessich, del primero, que postulara aportes para la construcción de una teoría general de la contabilidad (Mattesich, 2002, pp. 7-10).

Se separa de definiciones de la contabilidad, que la consideraron con criterio reduccionista, como una práctica económica para producir información y luego de controvertir las definiciones que la caracterizaron como arte, técnica, tecnología e incluso tecnología 
social expuso su propia definición, a partir de la cual construiría una estructura científica que busca eliminar todo tipo de reduccionismos. No reconoce la definición de la contabilidad como arte desarrollada por el AICPA en Estados Unidos (AICPA, 1965), por considerar que esta no corresponde al mundo de las artesanías o las bellas artes, no es objeto de contemplación estética (Garcia Casella, 2001, p. 69), ni es una técnica a pesar de que la incorpora en su estructura pero como aplicación de teorías científicas, ni la reconoce como ciencia aplicada sin corpus propio y tampoco como tecnología social porque tal definición se construyó sobre la consideración del derecho contable (Gil, 2007). Su definición está reiterada en varias de sus obras, en especial (Garcia Casella, 1997).

"La contabilidad es una ciencia factual, cultural y aplicada que se ocupa de explicar y normar las tareas de descripción, principalmente cuantitativas de la existencia y circulación de objetos, hechos y personas diversa en cada ente u organismo social y de la proyección de los mismos en vista al cumplimiento de metas organizacionales, a través de sistemas basados en un conjunto de supuestos básicos"

Se pueden tener observaciones sobre esta definición, en especial por su función de normar que puede considerarse base de regulación y su consecuencia de incurrir en obstáculos epistemológicos por autoridad o tradición del conocimiento (Bachelard, 1981) o por soportarse en supuestos básicos que eventualmente puede separarse de la realidad objetiva por incorporar fuertes influencias subjetivas, pero la definición incorpora elementos cruciales del trabajo de este autor, como la eliminación de reduccionismos que la limitan al campo financiero o a su aplicación exclusiva en las empresas, ampliando el horizonte del ente contable, al tiempo que se elimina otro reduccionismo al superar el pasado estableciendo conexiones con el futuro al considerar las metas de los entes.

La crítica al trabajo de Mattessich lo conducen a cuestionar su exposición de términos primitivos y supuestos básicos (Mattessich, 2002), eliminando las restricciones que los reducen al campo económico en diversos factores de su propuesta análoga mediante la cual establece que los usuarios de la contabilidad son múltiples y esta no puede reducirse a satisfacer las necesidades de información de uno o algunos (Garcia Casella, 2001, p. 1314); los entes contables se diferencian de los entes económicos en especial del concepto de empresa y son múltiples y complejos (Garcia Casella, 2001, pp. 14-16), aunque no se supera el marco de personas jurídicas o instituciones, pero por sobre todo cuestiona el campo de la contabilidad centrado en lo económico y lo extiende a lo social, los recursos naturales y la cultura (Garcia Casella, 2001, pp. 14-15).

Se incorpora en la crítica el asunto de la dualidad contable, comúnmente conocido como partida doble determinando que este elemento no puede limitar la capacidad de explicación, representación y predicción de la contabilidad (Garcia Casella, 2001, p. 16), considerando que esta solo reconoce situaciones de suma cero y existen hechos y fenómenos que no responden a esta estructura, aún dentro de una relación causa efecto. La contabilidad no se ocupa solo del registro de transacciones mercantiles, lo hace en relación 
con fenómenos sociales, ecológicos y culturales dado que su campo es amplio (Garcia Casella, 1997, p. 37).

Tabla 3. Estructura para la teoría general de la contabilidad propuesta por Carlos García Casella

\begin{tabular}{|c|c|c|c|c|c|c|c|c|}
\hline \multirow{2}{*}{$\begin{array}{l}\text { Supuestos } \\
\text { básicos }\end{array}$} & \multicolumn{8}{|c|}{ Términos primitivos } \\
\hline & Número & Valor & Medida & Tiempo & Objeto & Sujeto & Conjunto & Relación \\
\hline \multicolumn{9}{|l|}{$\begin{array}{l}\text { Medición } \\
\text { de preferencias }\end{array}$} \\
\hline \multicolumn{9}{|l|}{$\begin{array}{l}\text { Intervalos } \\
\text { de tiempo }\end{array}$} \\
\hline \multicolumn{9}{|l|}{$\begin{array}{l}\text { Objetos, hechos } \\
\text { y personas }\end{array}$} \\
\hline \multicolumn{9}{|l|}{ Sujetos } \\
\hline \multicolumn{9}{|l|}{ Entidad } \\
\hline \multicolumn{9}{|l|}{ Plan de cuentas } \\
\hline \multicolumn{9}{|l|}{ Fenómenos } \\
\hline \multicolumn{9}{|l|}{$\begin{array}{l}\text { Objetivos } \\
\text { de información }\end{array}$} \\
\hline \multicolumn{9}{|l|}{$\begin{array}{l}\text { Reglas } \\
\text { de valoración }\end{array}$} \\
\hline \multicolumn{9}{|l|}{$\begin{array}{l}\text { Reglas } \\
\text { de clasificación }\end{array}$} \\
\hline $\begin{array}{l}\text { Reglas } \\
\text { de entrada } \\
\text { y acumulación }\end{array}$ & & & & & & & & \\
\hline
\end{tabular}

Fuente: elaboración propia.

Igualmente se controvierten los problemas relacionados con la representación, generalmente reducida a estados financieros cuando debería hacerse relación a estados contables e incursionar en posibilidades diferentes a los cuadros de cuentas ampliando los horizontes propuestos por Cañibano (1979, pp. 79-82) para reconocer representaciones matriciales. Vectoriales y sagitales o la propuesta de Ballesteros sobre representaciones matriciales o por grafos (1979, p. 51.75). El tiempo es el siguiente tema de la crítica, no puede limitarse a la representación y análisis del pasado y el presente, debe incorporar el futuro, dado que la contabilidad es elemento determinante del logro de fines y metas (Garcia Casella, 2001, p. 68). 
La medición y valoración es el siguiente elemento de la construcción teórica y aunque el profesor García no precisa la diferencia entre estos dos conceptos establece que se debe aplicar en aspectos cuantitativos y cualitativos, partiendo de la afirmación de no reducción a una unidad de medida, pueden confluir diferentes para diferentes objetivos de la contabilidad (2001, pp. 16, 68, 197).

Un elemento adicional de la actividad crítica corresponde a su análisis de los problemas de la representación contable del ingreso y del capital, que ha generado múltiples controversias en la investigación contable, como es el caso de la polémica entre Macintosh y Mattessich (Franco, 2013). Macintosh discute si estos conceptos se originan en un imperialismo economicista que no permite reconocer otros elementos de la contabilidad como su componente social; aunque no llega a una proposición final, reflexiona sobre índices de bienestar humano de Naciones Unidas, considerando que la riqueza se puede concebir como vida extensa, creativa y saludable, medida por longevidad, conocimiento y nivel de vida de calidad; los ingresos se determinan por factores que contribuyen al mantenimiento y crecimiento de esa riqueza.

Con fundamento en estos elementos de una teoría general de la contabilidad procede el investigador a afirmar que esta determina la construcción de sistemas contables entendidos de los cuales se derivan los modelos contables que ordenan conceptualmente las observaciones derivadas de la experiencia, constituyendo representaciones complejas que explican el comportamiento de algún aspecto de la realidad.

El trabajo de García Casella incorpora una propuesta nacida de la crítica a las postulaciones del enfoque anglosajón anclado en la división del trabajo y el conocimiento sobre un extremo principio de especialidad y en lo fundamental a la propuesta teórica de Richard Mattessich, buscando nuevos horizontes y comprensiones amplias en términos de los elementos constitutivos del saber contable.

\section{Cuando surgió la escuela crítico-interpretativa}

La investigación contable tradicional ha tenido una perspectiva funcionalista en la que prevalece la investigación empírica, la cual ha tratado de construir soluciones específicas a problemas particulares. Es una investigación de tipo positivo, bien se ubique en el plano realista del positivismo objetivo donde la verdad se constituye como correspondencia entre el conocimiento y el objeto conocido o en lo positivo subjetivista que reconoce la institucionalidad objetiva de un ser social que permite desarrollos fundados en la relación fines medios determinante de la existencia de apríoris en la construcción social de la verdad. Frente a esta concepción aparecen tres nuevas perspectivas, el pensamiento crítico, el interpretacionismo y las relaciones contabilidad poder (Larrinaga, 1999). Otros autores reúnen estas perspectivas en una corriente crítico-interpretativa y ubican su origen a comienzos de la década de 1980 (Aquel, Cicerchia, \& Mileti) reconociendo como sus gestores a Peter Miller y Antony Hopwood. Pero en Colombia ya existía una amplia 
producción de esta naturaleza, sus primeros productos se conocieron a comienzos de la década de 1970.

Para desarrollar este argumento se toma como referente la noción de campo científico, consultada en un dosier que contiene la traducción del importante artículo publicado inicialmente en francés (Bourdieu, 1978), en el que se define el campo científico como un campo agonal, una lucha por el control de un saber reconocido socialmente y que incorpora todos sus elementos sociológicos e históricos, entre los cuales se puede contar en el caso de la contabilidad, los mercados, la regulación, las instituciones, el conocimiento y la educación, todos integrantes de tal campo. En tales condiciones la producción intelectual ubicada dentro de la noción de campo científico es una producción crítica si esta constituye el análisis, comprensión e interpretación de los elementos considerados.

Así se puede afirmar que la primera producción colombiana en el campo crítico interpretativo fue el texto de Jack Araujo Ensuncho en que se aborda el análisis del funcionamiento del mercado de servicios profesionales, del monopolio ejercido por ocho grandes firmas de auditoría que además controlan la producción simbólica solo accesible sus vinculados, determinando estrategias para la modificación de esas relaciones de poder (Araujo, 1976). Araujo avanzaría con su producción crítica, calificada de producción gris por no ser publicada en revistas indexadas, con trabajos relacionados a la crítica de la teoría de la contabilidad como "Elementos para una investigación en Contabilidad" y "La nueva contabilidad" en los años 1978 y 1979; aparecería además el primer trabajo crítico sobre el principio del costo en 1979 (Franco, 2011, pp. 11-31)

La producción crítica continuaría con documentos de trascendental importancia, que enfrentaron pretensiones de profundización de la segunda colonización contable mediante un documento titulado "Normas para la Presentación de Estados Financieros" auspiciado por organizaciones profesionales afines a los objetivos de colonización y el respaldo institucional de la Bolsa de Valores de Bogotá, la Asociación Nacional de Industriales, la Universidad Nacional y la naciente Asociación Colombiana de Facultades de Contaduría Pública Asfacop, frente al cual el Comité de Investigaciones de la Academia Colombiana de Contadores Públicos Titulados Adeconti, seccional Antioquia respondió con "Acerca de las normas para presentación de estados financieros", una fuerte controversia con los postulados conceptuales propuestos, un enfrentamiento con la concepción estadounidense sobre la información contable que fue finalmente archivada en medio de conflictos jurídicos. Todo esto ocurrido antes de 1980, el tiempo en que se reconoce a nivel mundial la emergencia de la corriente crítico-interpretativa.

En la década del 1980 la producción continuaría con trabajos de gran importancia como "Una aproximación a la naturaleza de la contabilidad" y "Sociedad, conocimiento y Contabilidad" ambos de Danilo Ariza Buenaventura, "El perfil del contador público" de Jorge Burbano, "Axiomas, principios fundamentales de la contabilidad de Roque Campo López y "El derecho a la información, una nueva teoría contable" todos los cuales vieron la luz hasta 1983. La producción continuó creciendo, permitió la emergencia de textos 
seminales en la teoría, la educación y la ética (Franco, 2011) y en la historia (Cubides, Gracia, Machado, Alberto, \& Visbal, 1999).

El proceso de producción de investigación crítica en contabilidad es objeto de un factor de impulso en el año 1987 cuando el Quinto Congreso Colombiano de Contadores Públicos decidió la conformación de una institución que liderará la investigación contable alternativa, decisión materializada en la constitución del Centro Colombiano de Investigaciones Contables CCINCO, el cual desde 1990, en la realización del Simposio sobre Investigación y Docencia ha logrado una amplia producción que lo consolida como centro de pensamiento crítico interpretativo, con la participación de múltiples investigadores que han alcanzado reconocimiento internacional. Esta historia está por construirse es un deber con la nación y con la investigación que debe sacar de la literatura gris la importante producción que por su naturaleza es ignorada unas veces por intencionalidades sesgadas, otras por rigor metodológico.

\section{Contabilidad integral y la concepción contamétrica.}

El texto de 1989 "Contabilidad Integral", es el más importante e influyente en el pensamiento contable colombiano, síntesis de preocupaciones construidas en la tradición de un trabajo académico, iniciado con un análisis crítico hermenéutico de la investigación contable, construyendo una clasificación temática y metodológica pertinente para abordar luego el problema de la normalización contable en sus dos escuelas fundamentales y estableciendo la existencia de un divorcio entre la teoría y la regulación, con mayor énfasis en el enfoque anglosajón que en el latino. Con base en la crítica histórica de la evolución de la investigación y la regulación se procede a la formulación del modelo de contabilidad integral, en el cual no se oculta la intención de construir una teoría general de la contabilidad basada en un enfoque hipotético deductivo que inicia con una formulación de principios o leyes básicas ubicados en el campo de la contadología o nivel teórico de la contabilidad a saber; Entidad, partida doble, sistemicidad y patrimonio social o polivalencia patrimonial (Franco, 1998, pp. 248-250).

Los mencionados principios constituyen una ruptura con el pensamiento tradicional, el concepto de entidad se constituye en el campo contable rompiendo su tradicional dependencia de aspectos jurídicos como la persona moral o jurídica o el ente económico constituido por la tradición, definiéndolo como el ente susceptible de ser informado, el cual se diferencia sustancialmente de las tradiciones para constituirse como objeto de información, en un nivel más abstracto y general. En lo relacionado con la partida doble se superan las concepciones mecánicas de igualdad de débitos y créditos convirtiéndolo en un concepto complejo que incorpora lo nominal y lo real, lo físico y lo financiero y especialmente la causalidad presente en los registros contables. La sistemicidad es la propiedad de un ente contable para ser representado como un sistema de cuentas, no en la concepción funcional y mecánica del concepto sino en sus características de elemento 
abstracto que soporta los procesos clasificatorios de acuerdo a objetivos de información. Finalmente se incorpora el principio de patrimonio social o polivalencia patrimonial en el cual se postula que los recursos pueden ser simultáneamente objeto de diferentes valoraciones de acuerdo con los objetivos de información, fundamentando la existencia de diversas representaciones en relación con los mismos hechos o fenómenos, que ocasionará el reconocimiento de diversas verdades contables simultáneas, elemento determinante del trabajo futuro.

La base conceptual de contabilidad integral pretende la ruptura con la tutela que consolidó a la contabilidad como servidumbre del derecho y la economía pretendiendo construirla como disciplina autónoma. Los principios formulados reconstruyen la contabilidad incorporando unos elementos de integralidad determinantes para la construcción del modelo contamétrico. Estos elementos se sintetizan en integridad cronológica permitiendo la construcción de representaciones de diferentes momentos, pasado presente e incluso futuro de manera integrada pero segmentada. Integridad métrica que permite la concurrencia de diversas bases de medición y valoración de manera integral pero segmentada; Integridad de objetos diversos de información, más allá de los aspectos eminentemente financieros e integralidad social en diversas comprensiones.

A partir de estos presupuestos teóricos se desarrolla el concepto de contametría concebida como "conjunto de normas, técnicas y procedimientos para la planeación, recopilación, procesamiento, evaluación, comunicación y control de información relacionada con flujos financieros, físicos, sociales y fenómenos económicos a través del tiempo" (Franco, 1998, pp. 250-251) y en un entorno específico. Este concepto ha venido evolucionando y hoy puede sintetizarse como la dimensión tecnológica de la contabilidad. La contametría se estructura en niveles general, particular y específico, abordando en el primero asuntos relativos a objetivos, características, normas generales y definiciones correspondientes con el entorno; en el nivel particular aborda aspectos relacionados con funciones, normas y definiciones particulares de acuerdo a objetos de información y en el específico incorpora normas técnicas incorporando aspectos relacionados con medición y valoración, estructura de sistema y subsistemas de información (Franco, 1998, pp. 279-315).

La integralidad cronológica queda determinada por la potencia de la contabilidad para informar su objeto a través del tiempo estableciendo su segmentación en planeación, presupuesto y flujos programados de efectivo, elementos que funcionan integradamente en este compartimiento de futuro y con las acciones de presente y pasado. En un segundo nivel se representan las transacciones (con sesgo financiero) en los niveles financiero y patrimonial en que el subsistema financiero reconoce contablemente por caja y el patrimonial lo hace por causación, estableciendo una diferenciación entre flujos reales de efectivo que permiten integración con la información de futuro, en especial con la correspondiente al presupuesto y los flujos programados de efectivo, aportando recursos analíticos y de control a la gestión; la dimensión patrimonial reconoce efectos de los flujos de efectivo y transacciones generadoras de mutaciones en los recursos que no incorporan flujos de efec- 
tivo pero constituyen realidades, de ninguna manera pronósticos como equivocadamente ejemplifica Ijiri y sus equipos de investigación (Glover, Ijiri, Levin, \& Jinghong, 2008) en sus importantes trabajos sobre la representación de hechos y pronósticos en contabilidad.

La integralidad valorativa se alcanza con base en subsistemas complementarios de información permitiendo su construcción en diferentes bases de valoración relacionadas con costo histórico ajustado, a valores de mercado o a otros valores estimados (valor presente neto). Los dos últimos constituyen pronósticos y esta información no puede sustituir ni mezclarse con la información de hechos, problemática actual de la regulación internacional, es información complementaria no sustitutiva. Esta información construida sobre diversas bases de valoración se fundamenta en la medición del subsistema básico, proporciona información de mercado determinante para las decisiones de muchos usuarios y por tanto se origina en intereses, permitiendo la representación de realidades diversas, las cuales no pueden mezclarse entre sí, ni con las mediciones básicas, son otras perspectivas y originan información multidimensional al presentarse de forma comparativa entre ellas, proporcionado nuevas posibilidades al análisis contable. Después se pudo entender, en especial por las lecturas de los textos de Macintosh que el enfoque constituye una concepción avanzada de contabilidad heteroglósica (Macintosh, 2002).

La integralidad objetual apenas queda mencionada en contabilidad integral y es desarrollada posteriormente (Franco, 2014) determinando que la contabilidad tiene la capacidad de construir representaciones que superen el aspecto financiero de los entes contables y en tal condición puede hacer representaciones de los factores de identidad social (Garcia, 1989), constituidos por el territorio, la cultura, la población y la economía en una consideración superior a la dimensión financiera, lo cual es posible por la falsación del concepto de moneda como unidad de medida y el establecimiento de diversidad de unidades, referidas a elementos financieros y flujos y stocks físicos. Esta integralidad objetual transforma de manera definitiva la contabilidad, elimina las creencias de que constituye un saber terminal y la sitúa en un escenario de disciplina científica en germen donde casi todo está por construir.

La integralidad social se determina por la construcción de representaciones de la participación social en la gestión de las organizaciones o del impacto de las actividades de estas sobre grupos sociales. Es factible la construcción de representaciones sobre origen y aplicación de productividad y de valor agregado por parte de diferentes actores sociales en las organizaciones a partir del reconocimiento derivado de la teoría personalista de las cuentas. El concepto de contametría incorporado, creado en contabilidad integral es diferente a las pretensiones de matematización de la contabilidad, no se trata de una aplicación matemática a las mediciones y valoraciones contables, aunque no descarta estas posibilidades, es una reconstrucción de las prácticas para fundamentarlas en bases teóricas y conceptuales que influyen aspectos instrumentales relacionados con clasificación, medición, valoración, revelación, interpretación y control. 
Contabilidad Integral dio los primeros pasos en un asunto capital de la contabilidad, la diferencia en los conceptos de medición y valoración tradicionales, que otros autores no abordaron antes. Se argumenta que Mattessich había solucionado este enigma (Mattessich, 2002). Esto es solo aparente, este autor asegura que diferenció estos elementos, pero lo real es que llamó medición a la clasificación y valoración al tradicional hibrido medición/valoración. Contabilidad Integral determina la medición como un problema ontológico, es objetiva y relacionada con la realidad material en tanto que la valoración es mediada por la realidad social. Esta diferenciación es determinante en la comprensión de la contametría entendida como desarrollo de una contabilidad tetra dimensional por incorporar dimensiones social, instrumental, temporal y praxiológica (Franco, 2014).

Se debe avanzar en el objetivo de señalar nuevos escenarios para los desarrollos teóricos de la contabilidad, construyendo unos primeros elementos relacionados con su definición, naturaleza, objeto de conocimiento y partiendo de este marco conceptual iniciar la construcción de la contametría como dimensión tecnológica para que sus prácticas abandonen por siempre los procedimientos empíricos y los métodos inductivos en la construcción de soluciones problema por problema como ha sido la tradición.

El trabajo es un desarrollo crítico de la teoría y técnica contable, constituyendo la hermenéutica el fundamento central del método de investigación, iluminando un camino de interpretaciones y comprensiones que permiten la identificación de anomalías en la evolución histórica del pensamiento contable, las cuales se constituyen en el objeto de la construcción de soluciones mediante una heurística positiva sobre el núcleo teórico y sobre el cinturón de seguridad que constituyen sus postulaciones técnicas (Lakatos, 1989).

En el proceso crítico se estudiaron las carencias históricas de la contabilidad, constituidas por la confusión entre conocimiento y regulación (Franco, 2011, pp. 51-60), su consideración como técnica y servidumbre del derecho y la economía (Franco, 1998, pp. 231-232), las anomalías surgidas de la fragmentación cognitiva contable (Franco, 1998, p. 243), así como en sus dimensiones instrumental, temporal y praxiológica, con el objetivo de formular fundamentos teóricos y métodos requeridos para superarlos.

El proceso contable conduce a una redefinición de la contabilidad, la caracterización de su naturaleza social que tiene por objeto la construcción de representaciones sociales sobre los factores de identidad social constituidos por el territorio, la cultura, la población y la economía (Franco, 1998, p. 231-247), señalando el fin de una etapa de segmentación que a partir de la división funcional del trabajo, con base en el principio de especialización, postulada por la administración científica, que estableció la existencia de diversas contabilidades con sus propios marcos conceptuales y procedimientos técnicos; la nueva concepción permite consolidar las condiciones para el desarrollo de la contabilidad como ciencia social. Es importante aclarar que desde la corriente crítico-interpretativa de la contabilidad, surgida en la década de 1970 en el Reino Unido se ha insistido en reconocer la naturaleza social de la contabilidad (Hopwood, 2000), pero no se han aportado desa- 
rrollos, dado que no existe una producción teórica ni tecnológica, pues su acción se ha concentrado en las acciones de interpretación y crítica (Franco, 2013).

Las reformulaciones teóricas se constituyen en marco conceptual de la contametría considerada como la dimensión tecnológica de la contabilidad en la que se abordan elementos relacionados con la clasificación, medición, valoración, revelación, interpretación, evaluación y control de hechos sociales relacionados con el territorio, la población, la cultura y la economía, posibilitando que a partir de una información objetiva, se desarrollen procesos de valoración y representación subjetivo-objetivos que consulten la dimensión temporal, los intereses y valores de los grupos de interés y fundamenten sus evaluaciones desde sus propias perspectivas, eliminando sesgos hacia determinado grupo como ha ocurrido en la contabilidad financiera con los agentes del financiamiento. Algunos autores han abordado algunas temáticas enunciadas como procesos, pero resulta importante afirmar que solo lo han hecho desde la perspectiva de la economía (García, 2002) y desde el derecho (Mattesich, 2002) si se considera que la relación de agencia determina que la contabilidad describe las relaciones principal-agente.

Se abre un escenario extenso para la investigación en un programa contamétrico en que no es posible avanzar con diligencia por esfuerzos solitarios y requiere la formación de comunidad y el esfuerzo compartido de investigadores, universidades y naciones en esta prospectiva.

\section{Hacia la consolidación de una escuela latinoamericana}

Las tradiciones contables surgidas en América Latina de las secuenciales colonizaciones que han reducido la contabilidad a su componente financiero, la interpretación al análisis financiero y la evaluación a la coherencia de los informes con su base comprensiva. Este trabajo de revisión ha permitido la identificación de escuelas de pensamiento contable latinoamericano, que en una ruptura epistemológica con el saber tradicional pretenden rectificar los errores del pasado, los obstáculos epistemológicos (Bachelard, 1981, pp. 281-287) pero también incorporar nuevas concepciones y métodos en el proceso de construcción de una ciencia contable de naturaleza social.

La contabilidad así considerada incorpora nuevas dimensiones en su naturaleza y aplicación, permite la reflexión, comprensión e interpretación de las proposiciones científicas de los aportes de las escuelas latinoamericana y sus investigadores, buscando una nueva síntesis constructora de un saber liberatorio que integra las dimensiones sociales, instrumentales, temporales y axiológicas, aportando a la construcción de calidad de vida (Martin, 2014).

Existe un factor común en las tres escuelas identificadas y se relaciona con la construcción de una teoría general de la contabilidad a partir de la cual se construyan sistemas y modelos especiales de acuerdo a requerimientos sociales de información, análisis, explicación y predicción. 
El trabajo se ha iniciado, hay grandes avances desde las diferentes escuelas identificadas, lo pendiente es desafiante pero gratificante, al fin es posible la consolidación de la contabilidad como disciplina científica de naturaleza social y se puede abandonar el escenario de las conjeturas, de las visiones parciales para construir el nuevo campo del saber.

Se requiere construir una síntesis enriquecida con el abundante material crítico interpretativo, en especial por esa tendencia precursora en América Latina originada en Colombia mediante la acción de investigadores solitarios y que ha alcanzado profundos desarrollos en la actividad todavía no cohesionada de los investigadores vinculados al Centro Colombiano de Investigación Contable CCINCO. Las formidables posibilidades de transformación del pensamiento contable que anticipan un paradigma en crisis y la emergencia de uno nuevo están a nuestro alcance.

\section{Agradecimientos}

El autor expresa su gratitud a los autores que lo inspiraron y en especial al filólogo Jesús Suárez por sus aportes en la redacción de este artículo.

\section{Declaración de divulgación}

El autor manifiesta no tener ningún conflicto de intereses para la publicación de este artículo, asociado a la línea de investigación: Epistemología y regulación contable.

\section{Financiamiento}

Universidad Libre, Bogotá, Colombia.

\section{Sobre ell autor}

Rafael Franco Ruiz, Docente-investigador Universidad Libre, graduado en Contaduría Pública de la misma universidad y con Maestría en Administración Económica y Financiera de la Universidad Tecnológica de Pereira, las cuales cuentan con acreditación institucional de alta calidad

\section{Referencias}

AICPA. (1965). Principios de contabilidad de geberal aceptación. México D. F.: Instituto Mexicano de Contadores Públicos.

Aquel, S., Cicerchia, L., \& Mileti, M. (s.f.). http://www.econ.uba.ar/www/institutos/epistemologia/marco_archivos/trabajos_XV_archivos/Aquel,\%20Cicerchia\%20y\%20Mileti-\%20PERSPECTIVAS\%20 CONTEMPOR.pdf. Recuperado el 2 de Mayo de 2014, de http://www.econ.uba.ar/www/institutos/epistemologia/marco_archivos/trabajos_XV_archivos/Aquel,\%20Cicerchia\%20y\%20 Mileti-\%20PERSPECTIVAS\%20CONTEMPOR.pdf: V

Araujo, J. (1976). Contaduria pública monopolio yanky en colombia. Medellín: Ealon. 
Ariza, D. (1976). Historia de la contabilidad. Bogotá: Universidad Nacional S.P.

Bachelard, G. (1981). La formación del erspiritu cientifico. Bogotá: Siglo XXI.

Baker, R. (2011). A discussion of the positions poststructuralist and postmodernist in the work of Norman Macintosh. Critical perspectives on acounting, 110-117.

Balboa, P., Piedra, F., \& Margarita, M. (2002). Del monismo al pluralismo contable. Revista internacional de filosofía y epistemología de las ciencias económicas EVEPYEIA, 124-165.

Ballesteros, E. (1979). Teoría y Estructura de la nueva contabilidad. Madrid: Alianza editorial.

Besserat, D. S. (2004). Contabilidad por fichas en el antiguo medio oriente. En J. Suarez, Arqueología e historia de la contabilidad (pp. 51-62). Bogotá: Universidad INCCA de Colombia.

Bourdieu, P. (1978). El campo científico. REDES, Dossier de investigación en ciencias sociales, 30-60.

Cañibano, L. (1979). Teoría actual de la contabilidad. Madrid : Ediciones ICE.

Coelho da Rocha, L. F. (2004). Aportes sobre la doctrina científica del neopatrimonialismo contable. Revista Legis de contabilidad y auditoría, 129-144.

Cook, A. (1988). Normas de contabilidad, un fenómeno de nuestro tiempo. Teuken.

Cubides, H., Gracia, E., Machado, M., Alberto, M., \& Visbal, F. (1999). Historia de lacontaduría pública en Colombia Siglo XX. Bogotá : Universidad Central.

Díaz, R. y. (1980). La contaduría pública en Colombia. Bogotá: Universidad Gran Colombia S.P.

Donoso, A. (2003). Doctrina contable en el siglo XVIII y su influencia en los proyectos de reforma contable de la época. Revista española de financiación y contabilidad, 797-832.

Engels, F. (1982). Origen de la familia, la propiedad privada y el estado. Bogotá: Latina.

Fedriani, E., \& Tenorio, A. (2004). Los sistemas de numeración maya, azteca e inca. Lecturas matemáticas vol 25, 159-190.

Franco, R. (1998). Contabilidad integral. Pereira: Investigar Editores.

Franco, R. (1998). Contabilidad Integral. Pereira: Investigar editores.

Franco, R. (2011). Reflexiones contables: teoría, regulación, educación y moral. Bogotá: Universidad Libre.

Franco, R. (2011). Reflexiones contables: teoría,regulación, educación y moral. Bogotá: Universidad Libre.

Franco, R. (2012). Fiscalización estratégica de arquitectura organizacional. Bogotá: Universidad Libre.

Franco, R. (2013 A). Teoría del Régimen Internacional en Contabilidad. Lúmina 13, 8-29.

Franco, R. (2013). Aportes del posestructuralismo y el posmodernismo al desarrollo del pensamiento contable. Lúmina 14, 54-87.

Franco, R. (2013). La polémica Macintosh Mattessich. Revista Cientifica "General José María Cordova", sin editar.

Franco, R. (2014). El concepto de contametria. Criterio libre, S.P.

Franco, R., \& Alvarez, H. (1988). Principios de contabildad para Colombia. Armenia: Investigar.

Gadamer, H. G. (1999). Verdad y método tomo I. Salamanca: Sigueme.

Garcia Casella, C. (1997). Enfowue multi-paradigmatico de la contabilidad:Modelos, sistemas y prácticasdeducibles Para diversos contextos. Buenos Aires: Universidad de Buenos Aires.

Garcia Casella, C. (2001). Elementos para una teoróa general de la contabilidad. Buenos Aires: La ley.

García, M. (2002). Contabilidad y circulación económica: una visión nueva y unificada de la contabilidad. Madrid: Prentice Hall.

Garcia, N. (1989). Culturas hibridas. México: Grijalbo. 
Gertz, F. (1976). Origen y evolución de lacontabilidad. México D.F.: Trillas.

Gil, J. (2007). El derecho contable como sistema de normas. ASFACOP, 89-134.

Glover, J., Ijiri, Y., Levin, C., \& Jinghong, P. (2008). Separación de los hechos y los pronósticos en los estados financieros. Innovar 18-31, 135-146.

Hopwood, A. (2000). Understanding ${ }^{\circledR}$ nancial accounting practice. Accounting, Organizations and Society 25, 763-766.

Lakatos, I. (1989). La metodología de programas de investigación cientifica. Madrid: Alianza Universidad.

Larrinaga, C. (1999). Perspectivas alternativas de investigación en contabilidad: una revisión. Revista de contabilidad, 103-131.

Levine, C., \& Ijiri, Y. (2004). Solo hechos (y los pronósticos). Harvard Business Review 6, 18-18.

Lopes de Sa, A. (1990). Introdução à teoria das funções sistemáticas do patrimônio. Cuadernos aragoneses de economía, 155-79.

Lopes de Sa, A. (1992). Teoría General del Conocimientocontable. Madrid: ICAC.

Lopes de Sa, A. (2003). Bases de las escuelas europea y norteamericana frente a la cultyura contable y la propuesta neopatrimonialista. Revista internacional Legis de contabilidad y auditoría, 69-92.

Macias, H., \& Moncada, T. (2011). Referentes para la investigación contable latinoamericana: Una mirada al campo cientifico anglosajón. México: XVI Congreso interancional de contaduría, adminstración e informática.

Macintosh, N. (2002). Accounting, Accountants and Accountability. Poststructuralist positions. Londres: Routledge.

Martín, V. (29 de Marzo de 2014). LA CONTABILIDAD: ¿CIENCIA SOCIAL? Debates sobre saber contable, empresa y responsabilidad social. S.P. Rionegro, Antioquia, Colombia: S.P.

Masi, V. (1943). La ragioneria come scienza del patrimonio. Bologna: Padova.

Masi, V. (1962). Teoría y metodología de la contabilidad. Madrid: E.J.E.S.

Mattesich, R. (2002). Contabilidad y métodos analiticos. Buenos Aires: La ley.

Mattessich, R. (2002). Contabilidad y métodos analiticos, medición y proyección del ingreso y la riqueza en la microeconomía y el la macroeconomía. Buenos Aires : La ley.

Morales, F. J. (2006). Los esfuerzos en latinoamérica hacia la armonización contable internacional: especial atención en la integración Argentina, Brasil Chile. Contabilidad y auditoría, 147-155.

Súarez, J. (2014). Antonio Lopez de Sa filósofo de la contabilidad. Bogotá: S.P.

Suárez, J.; Franco, R.; Acosta, R. \& Alonso, H. (2017). Nariño el Contador, el Precursor-Libertador: la Ilustración, la Independencia. Bogotá: Sello Editorial EMIC, Escuela Militar de Cadetes "General José María Córdova”.

Tirado, A. (1976). Introducción a la historia económica de Colombia. Medellín: La Carreta.

Tofler, A. (1980). La tercera ola. Barcelona: Plaza \% Janes.

Villulenga de Gracia, S. (2013). La partida doble y el cargo y data como instrumentos de un sistema de información contable y responsabilidad jurídica integral, según se manifiesta en fuentes documentales de la Catedral de Toledo (1533-1613). Revista Contabilidad, 126-135. 